\title{
EFFECTIVENESS OF USING THE METHOD OF ARTIFICIAL INTELLIGENCE IN MAINTENANCE OF ICT SYSTEMS
}

\author{
Tomasz GOŚCINIAK \\ Dimension Data \\ Krzysztof WODARSKI \\ Silesian University of Technology
}

\begin{abstract}
:
Reliability of production systems in enterprises is increasingly dependent on the availability of ICT systems that supervise them. The research presented in this paper focuses on the improvement of the availability of ICT systems by identifying possibilities of further automation of their maintenance processes. After preliminary research, it has been concluded that the possibility of further automation by using artificial intelligence methods to support decision making regarding the improvement of ICT systems is worth considering. The main aim of the paper was to carry out research into the possibilities of using and implementing artificial intelligence to support decision making regarding the improvement of ICT systems.
\end{abstract}

Key words: Information and Communication Technology, Al methods, Information Technology Infrastructure Library, Reliability of production systems

\section{INTRODUCTION}

In today's economy, automation of production systems very often depends on the available information technologies. This is due to the fact that globalisation of the IT (Information Technology) market and migration of most IT services to the cloud management model lead to a growing importance of ICT (Information and Communication Technology) systems [16]. Often, the model of cooperation between the processing and management subsystems is based on the ICT system that supervises the production system (Fig. 1).

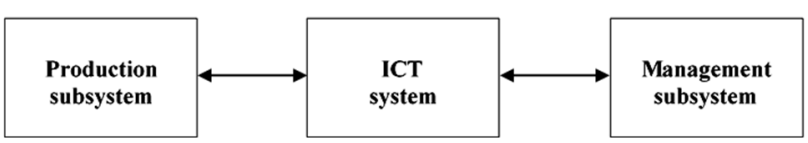

$\longleftrightarrow$ Decisions of the management Staff and feedback

Fig. 1 Diagram showing links between production and ICT systems

Source: own study based on [4].

This dependence means that the reliability of IT-supported production systems is largely a result of the availability of the ICT systems that support them. ICT systems are required to operate practically uninterruptedly. There is nothing unusual in that, as systems that control factories, power lines or emergency reports simply cannot cease to work.
Availability of ICT systems relates to their maintenance. Nowadays, the world's leading methodology for maintenance of ICT systems is Information Technology Infrastructure Library - ITIL $[5,6,7]$. This methodology includes sets of best practices for processes of ICT systems' maintenance with the most important ones being [8]:

- event management,

- incident management,

- problem management.

Fig. 2 presents a model of ICT systems' maintenance.

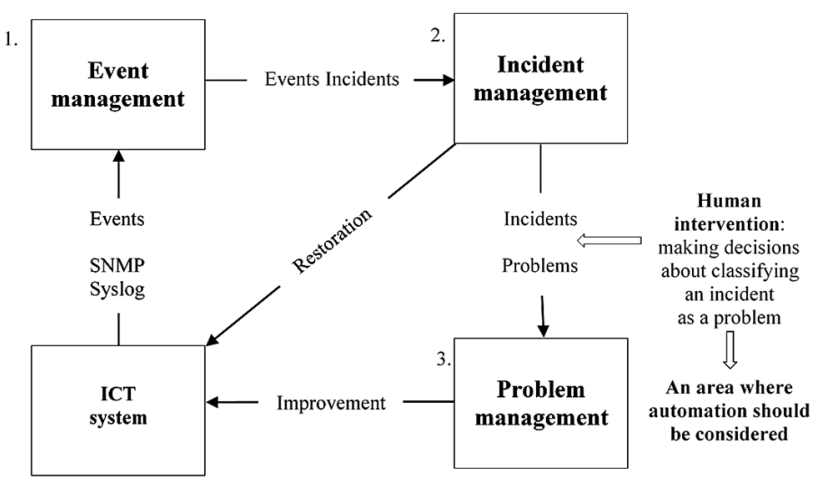

Fig. 2 Model of ICT systems maintenance

The model shows the three above-mentioned most important processes of ICT systems' maintenance, along with relationships among them, that result from temporal sequences, as well as fulfilled functions and executed 
tasks. In general terms, the relationships between different processes of ICT systems' maintenance can be described as follows:

1. The process of event management focuses on data collection from ICT systems, its preliminary analysis, filtration and transmission of appropriate information to the process of incident management. Information available from protocols of ICT systems monitoring, such as syslog and SNMP, generated by ICT systems, is gathered in the process of event management. Such information may inform about the status of devices or irregularities in their operation. All pieces of information obtained this way are classified as events. The effect of the operation of the event management process is proper understanding of the messages available from SNMP and syslog protocols and their correct interpretation.

2. The information from the event management process is transmitted to the incident management process where it is classified as incidents. The incident management process is responsible for eliminating failures that occurred in ICT systems. The priority here is to restore the operation of ICT systems using any method, which often means that temporary solutions that are available at that moment are used, rather than the most suitable ones in terms of elimination of the failure cause. The effect of the operation of the incident management process is elimination of the failure in ICT system, i.e. solving the incident.

3. The process of problem management focuses on searching for areas in ICT systems where the operation of the ICT system should be improved. Searching for such areas for potential improvement is mainly based on the knowledge and experience of the analyst, who indicates incidents for further engineering analysis and possibly implementation of improvements.

Summing up, the information gathered in the process of incident management is analysed in the process of problem management in terms of its negative impact on ICT systems and based on the analysts' knowledge and experience is classified as a problem. Problems are referred for further analysis in order to work out improvements of ICT systems that result in the elimination of causes to prevent the occurrence of such incidents in the future. Improvements of ICT systems, as one of the outputs of the process of problem management, should be implemented into the ICT system in order to obtain positive effects of the improvements and thereby reduce the number of incidents and failures, as well as increase the availability of ICT systems.

Each of the above-mentioned processes fulfils a different role, and they cooperate with one another to constitute the process of ICT systems maintenance. The process of event management is responsible for gathering and interpreting events occurring in ICT systems. The role of the incident management process is to eliminate the existing failures. The process of problem management, through implementation of improvements, results in reduction of the number of incidents, i.e. failures. This has a positive impact on availability of ICT systems, and consequently on the improvement of reliability of an enterprise's production system. In this process, an analyst analyses the incident and decides on its qualification as a problem.

The speed and accuracy of the analyst's decision depend on their knowledge and experience as well as on the use of appropriate methods (e.g. chronological analysis, analysis of trends, Pareto method) and tools (spreadsheets, among other things) in their work. The application of such methods and tools has a positive impact on the costs and speed of the process and contributes to improvement of reliability of production systems. It seems, however, that it is possible to further improve this process by using more advanced mathematical methods, i.e. artificial intelligence methods. Fig. 2 presents the area where it is worth examining the possibilities of further automation of the processes of ICT systems maintenance for improving their availability, which will have a positive impact on the reliability of production systems $[11,15]$. This area refers to decision making regarding classification of an incident as a problem.

Research conducted by DimensionData [2] shows that human beings make the most errors (32\%) in ICT systems maintenance. Given that, it can be concluded that there is a need to develop solutions that will support analysts of ICT systems and allow them to make accurate decisions more quickly [13].

This paper presents research findings that should provide a basis for the use of artificial intelligence methods for further automation of the processes of ICT systems maintenance and improvement of the reliability of production systems.

\section{RESEARCH METHODOLOGY AND CHARACTERISTICS OF THE RESEARCH SAMPLE}

In order to achieve the formulated aim, the research addresses two research issues as follows:

1) specifying the artificial intelligence method that can be used in ICT systems' maintenance to support decision making regarding improvement of such systems as part of the problem management process,

2) adapting a specific artificial intelligence method for its use to support decision making regarding improving ICT systems as part of the process of problem management.

With regard to the first issue, an analysis of the process of incident management in ICT systems was conducted in order to select the artificial intelligence method that can be used to support decision making in the area of improvement of ICT systems in the process of problem management. In order to define standards for maintenance of ICT systems in an enterprise, an analysis of the processes of their maintenance was conducted in an IT company that is a world leader in online technologies. The basis for defining the standards was study of procedures and instructions - the so-called runbooks of the company. The analysis has shown that most of the signals that are available from the process of incident management have quantifiable values. This implies that artificial intelligence methods based on quantifiable signals should be used for their 
analysis $[9,10]$. The method must also have a generalization property, as its decisions are based on data outside of the training dataset. In addition, it must be able to make decisions relying on incomplete data, as not all of the signals available in the process of incident management are quantifiable or taken into account by analysts. For that reason, neural networks were selected as the artificial intelligence method that can be used to support decision making regarding improvement of ICT systems $[12,14,17]$.

With regard to the second research issue, research was conducted in three successive stages of a research process. The first stage involved surveys among experts that aimed to determine the significance and usefulness of signals from the incident management process in terms of the possibility of using them to support decision making regarding improvement of ICT systems by means of neural networks. The surveys resulted in identification of 8 significant signals that, according to the experts, have the biggest impact on decision making regarding qualification of incidents for further analysis as part of the process of problem management, and thereby decisions on improvement of ICT systems (Fig. 3).

Analysis of usefulness of such signals in terms of their use in neural networks resulted in identification of 4 signals, namely:

- impact - impact of an incident on ICT systems (classified into four categories: Widespread, Large, Localized, Individual),

- urgency - urgency of an incident: Critical, High, Medium, Low,

- TTR OK - shows whether the contractual condition to send notification to end customer within the agreed time has been met,

- TTN OK - shows whether the contractual condition to restore the operation within the agreed time has been met.
The third stage involved surveys among experts that aimed to collect expert knowledge on the four distinguished signals determining the improvement of ICT systems. Based on the results of these surveys it has been concluded that there is expert knowledge in the area of the 4 identified signals that can be consolidated and written in a form understandable to neural networks. In order to collect expert knowledge based on which decisions are made to classify an incident as a problem, i.e. to improve ICT systems, surveys have been conducted. They have been conducted among 14 experts employed as analysts in the company (leader in online technologies), who participated in the surveys that aimed to determine the significance of signals in the maintenance of ICT systems. The aim of the surveys was to collect expert knowledge that could be used to choose appropriate incidents for further analysis in the process of problem management based on the parameters of their impact, urgency and compliance with contractual obligations TTN OK (Time to Notify) and TTR OK (Time to Restore). The surveys have shown slight differences among the respondents regarding the selection of incidents based on the signals analysed. This indicates equal training of the analysts. The analysts responded identically when classifying incidents with the highest impact and urgency, i.e. priority. Slight differences were seen as the impact and urgency of incidents decreased. Differences are particularly visible in areas where the TTR OK and TTN contractual parameters have not been met in the case of lower priority incidents.

rounded down to 0 if the average value is from 0 to 0.49 (9). Based on the results of these surveys it has been concluded that there is expert knowledge in the area of the signals being analysed that can be consolidated and written in a form understandable to neural networks. This is a basis for building and implementing a neural network for decision making regarding improvement of ICT systems.

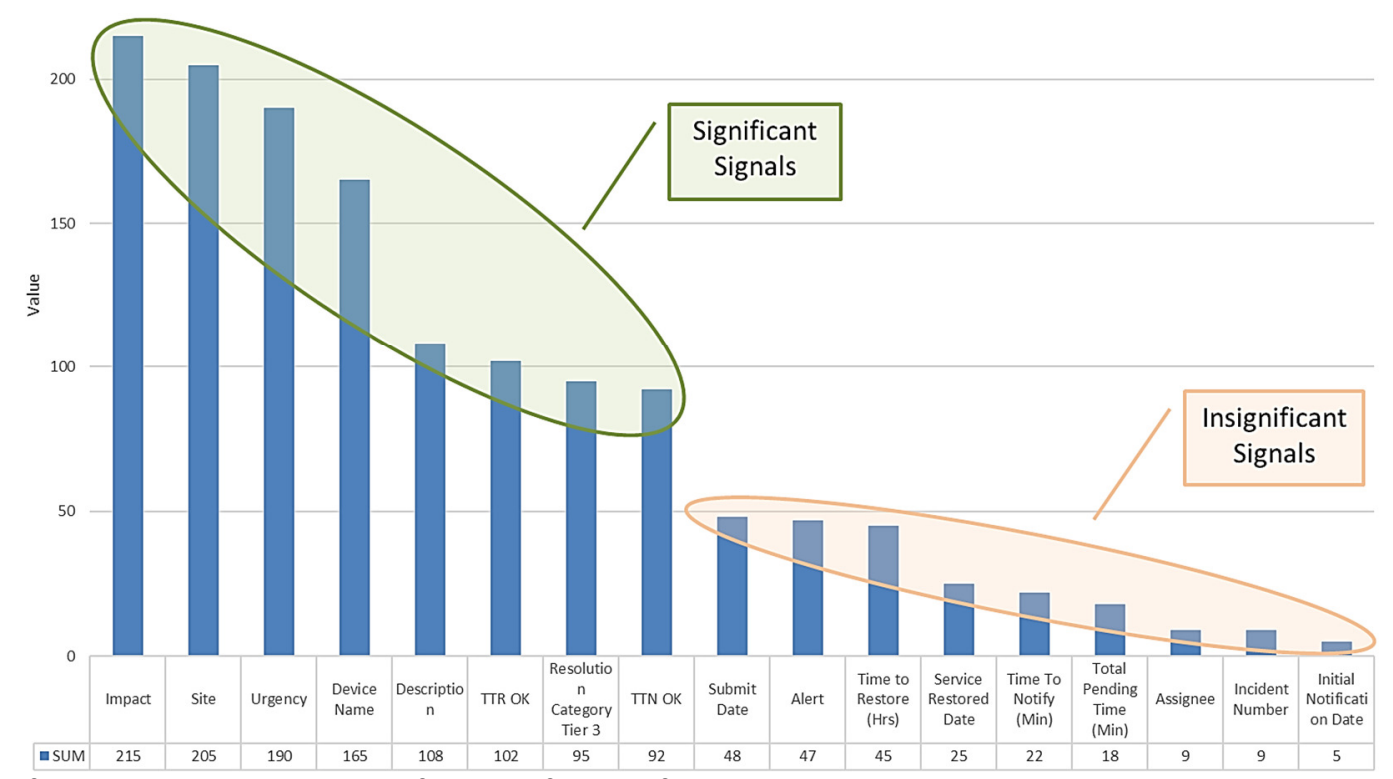

Fig. 3 Results of the surveys with indication of the significance of signals 
In order to build training datasets of an artificial intelligence method based on the collected survey data, the data should be consolidated. In data consolidation, the data is averaged using an arithmetic method and rounded up to 1 if the average value is from 0.5 inclusive to 1 or rounded down to 0 if the average value is from 0 to 0.49 (9). Based on the results of these surveys it has been concluded that there is expert knowledge in the area of the signals being analysed that can be consolidated and written in a form understandable to neural networks. This is a basis for building and implementing a neural network for decision making regarding improvement of ICT systems. The fourth stage focused on implementation of the neural network method into the decision-making process regarding improvement of ICT systems. First, a neural network has been built, which required:

- development of a dataset for training the neural network based on the expert knowledge collected, and data normalization to adapt it to the requirements of processing by neural networks,

- selection of the optimum configuration of the neural network by comparing the values of MSE parameters of different neural networks in the process of training them.

The analyses have shown that the most effective neural network to be used in incident analysis and decision making regarding classification of incidents as problems is the network with the following parameters: the number of input neurons -10 , the number of output neurons -1 , the number of neurons in the hidden layer - 20, the use of BIAS in neurons, activation function - sigmoid, learning method: back-propagation using momentum. A neural network with the above parameters, created in the "Neuroph Studio" package, is presented in Fig. 4.

The network was then used in practice in three instances involving ICT systems maintenance in companies of various profiles of activity and sizes. The aim of using the neural network built in practice was to verify its correct operation in the context of time and accuracy of decision making regarding improvement of ICT systems. The results obtained were compared with time and accuracy of the decisions made by analysts (experts) of a selected company - leader in online technologies.
Based on three instances, it can be concluded that the use of the neural network built in the practice of maintaining ICT systems makes it possible to take faster decisions on improvement of such systems. The working time of the neural network (a few seconds) for decision making is significantly shorter than the working time of ICT systems' analysts (from 1 day to 6 days).

With regard to the accuracy of the decisions made, synthetic collection of the findings (Table 1) enabled indication of the following patterns:

1. There is high variability in the correspondence of the results achieved by the neural network with the results achieved by the analysts in different months, defined as \% of correspondence in the different months.

2. In each case, the number of incidents indicated by the neural network is smaller than the number of incidents selected by the analysts.

3. There is high variability in the correspondence across instances, measured as difference of the average \% of correspondence.

4. The mean-squared error (MSE) is comparable for all the instances and consistent with the MSE of the neural network during its learning.

Table 1

Accuracy of the neural network's decision making regarding improvement of ICT systems Example

1

\begin{tabular}{lccc}
\hline $\begin{array}{l}\text { Average \% of cor- } \\
\text { respondence } \\
\text { average (C) }\end{array}$ & $85 \%$ & $51 \%$ & $41 \%$ \\
$\begin{array}{l}\text { Mean-squared } \\
\text { error-MSE }\end{array}$ & 0.002226031 & 0.003673164 & 0.006463709 \\
\hline
\end{tabular}

It has been found that the impact of a single error on the final result achieved by the neural network in the different instances depends on the overall number of problems in a given month. The level of MSE for the neural network model in the different instances is comparable. This suggests that such an error has been caused by factors that have not been taken into account in the model of the neural network built.

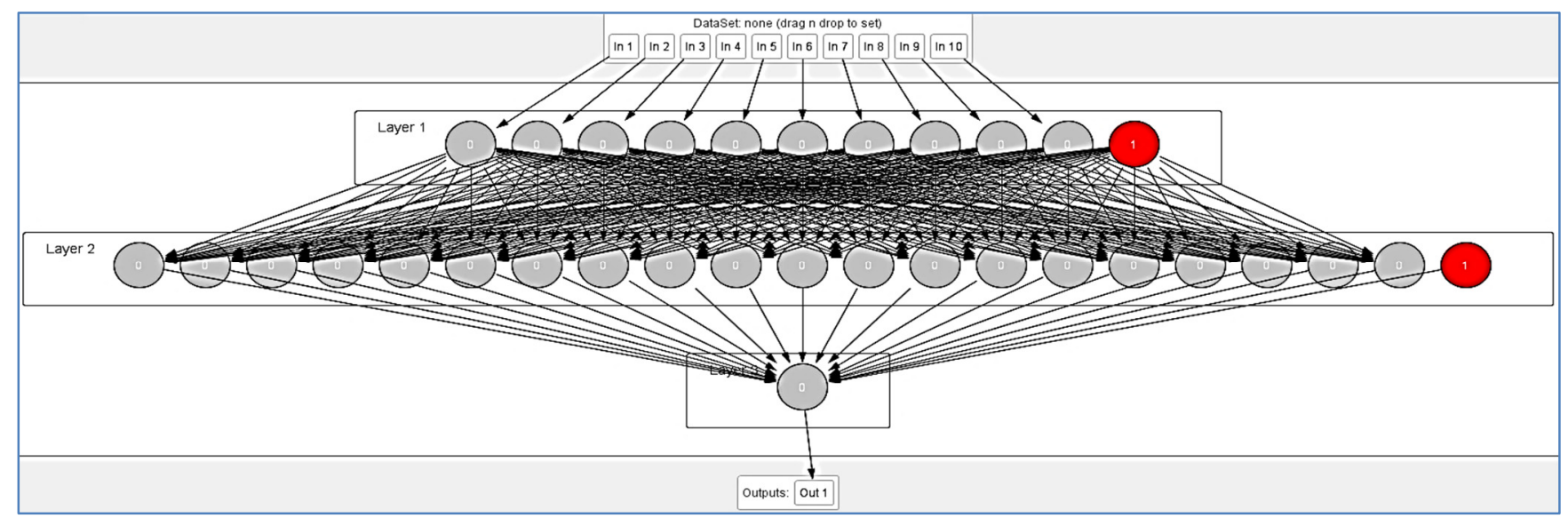

Fig. 4 Neural network used in analysis of incidents and decision making regarding classification of incidents as problems 
That's why additional consultations with analysts have been conducted. It has been found that in the three instances that were used to verify the operation of the neural network there were additional factors at play when decisions about qualifying an incident as a problem were made. In particular, the analysts highlighted:

- customer intervention: the customer was changing the rules for selecting incidents for further analysis for reasons that had not been taken into account in the process of ICT systems maintenance, and by extension in the neural network built.

- internal intervention: other teams that participate in work with individual customers impacted the decision to qualify selected incidents as problems for further analysis,

- business factor: non-codified factor (e.g. VIP location) that had to be handled with higher urgency than defined by the standard procedure,

- customer reputation: non-codified factor - temporary requirement from the customer's PR.

This shows that the more the company is prone to take into account non-codified factors, the lower the correspondence between the results of the neural network's work and those of the analysts. Taking into account the verified results for the three instances analysed with reference to the accuracy of the decisions made, the following patterns can be indicated (Table 2):

1. The level of correspondence between the results achieved by the neural network and the results achieved by the analysts in different months, defined as \% of correspondence in different months, is significant.

2. In each instance, the number of incidents indicated by the neural network is slightly smaller than or equal to the number of incidents selected by the analysts.

3. There is a significant decrease in the variability in correspondence across the instances, measured as difference of the average \% of correspondence.

4. The mean-squared error (MSE) is comparable for all the instances and consistent with the MSE of the neural network during its learning.

Table 2

Accuracy of the neural network's decision making regarding improvement of ICT systems Example

\begin{tabular}{lccc} 
& \multicolumn{3}{c}{ Example } \\
& $\mathbf{1}$ & $\mathbf{2}$ & $\mathbf{3}$ \\
\hline $\begin{array}{l}\text { Average \% of cor- } \\
\text { respondence }\end{array}$ & $91.1 \%$ & $80.0 \%$ & $83.3 \%$ \\
$\begin{array}{l}\text { average }(\mathrm{C}) \\
\begin{array}{l}\text { Mean-squared } \\
\text { error-MSE }\end{array}\end{array}$ & 0.002226031 & 0.003673164 & 0.006463709 \\
\hline
\end{tabular}

\section{CONCLUSIONS}

The comparative analysis of the obtained results shows that a neural network can be used to support the work of analysts, as it provides them with a basis for taking accurate decisions on the improvement of ICT systems in a fast manner.

However, it should be stressed that, in real life, there are other signals that have not been taken into account in the neural network, as well as additional factors that cannot be predicted and thereby included in the neural network, therefore, it is not possible to completely replace the work of analysts and rely on the neural network to automatically take decisions on improvement of ICT systems. Based on the results, it has also been concluded that the use of a neural network may bring a number of other benefits in terms of maintenance of ICT systems, such as normalization of:

- standards for maintenance of ICT systems for ensuring higher availability of such systems (implementation of the neural network will force the use of the same decision-making criteria in qualification of incidents for the process of problem management),

- problem management in various locations of an enterprise, especially when they are in different countries and direct communication is difficult.

- services of ICT systems maintenance provided to various customers and industries, leading to their increased compliance with best practices in the area of selecting incidents for the problem management process.

\section{REFERENCES}

[1] Białko M., Sztuczna inteligencja i elementy hybrydowych systemów ekspertowych, Politechnika Koszalińska, Wydawnictwo Uczelniane, Koszalin 2015.

[2] DimensionData. Network Barometer Report, www.dimensiondata.com, https://www.dimensiondata.com/Global/Downloadable\%20Documents/Network\%20Barometer\%20Report\%202014.pdf. 2015.

[3] Gościniak T., Analiza sygnałów z procesu zarządzania incydentami w systemach ICT i ich wykorzystanie w podejmowaniu decyzji z użyciem metod sztucznej inteligencji, Zeszyty Naukowe Politechniki Śląskiej, seria Organizacja i Zarzqdzanie, vol. 78, Gliwice. 2015.

[4] Gościniak, T., Zarządzanie procesami naprawczymi w systemach informatycznych operatorów telekomunikacyjnych. Zeszyty Naukowe Politechniki Ślqskiej, seria Organizacja i Zarzqdzanie, vol. 70, Gliwice. 2014.

[5] Information Technology Infrastructure Library, 2017, ITIL jest najpopularniejszq metodologiq zarzqdzania usługami ICT w przedsiębiorstwie, https://www.axelos.com/best-practice-solutions/itil. 2017.

[6] ITIL Continual Service Improvement, OGC, TSO (The Stationery Office), London. 2007.

[7] ITIL Glossary and Abbreviations, 2011, English Version, Axelos, https://www.axelos.com/Corporate/media/Files/Glossaries/ITIL_2011_Glossary_GB-v1-0.pdf.

[8] ITIL Service Operations, OGC, London, TSO (The Stationery Office), 2007. pp. 35-103.

[9] K. Michalik, Systemy ekspertowe we wspomaganiu procesów zarzqdzania wiedzq w organizacji, Wydawnictwo Uniwersytetu Ekonomicznego w Katowicach, Katowice. 2014.

[10] Łęski J., Systemy neuronowo-rozmyte, Wydawnictwa Naukowo-Techniczne, Warszawa, 2008. 
[11] Lewandowski J., Skołud B., Plinta D., Organizacja systemów produkcyjnych, Zarzqqdzanie i Inżynieria Produkcji, Polskie Wydawnictwo Ekonomiczne, Warszawa, 2014.

[12] Markowska-Kaczmar U., Kwaśnicka H., Sieci neuronowe w zastosowaniach, praca zbiorowa, Oficyna Wydawnicza Politechniki Wrocławskiej, Wrocław. 2005.

[13] Nawrocki T., Jonek-Kowalska I., Fuzzy approach to corporate potential innovativeness assessment, W: International Conference on Management - Trends of management in the contemporary society, Brno, June $9^{\text {th }}-10^{\text {th }} 2016$. Peer-reviewed conference proceedings. Ed. by Sylvie Formankova. Brno: Mendelova univerzita v Brne, 2016, pp. 321-324.

\section{Tomasz Gościniak, PhD.}

\section{Dimension Data}

Global Delivery Center

Prague, Czech Republic

dr hab. inż. Krzysztof Wodarski, prof. PŚ.

Silesian University of Technology

Faculty of Organization and Management Institute of Management, Administration and Logistics ul. Roosevelta 26, 41-800 Zabrze, Poland e-mail: krzysztof.wodarski@polsl.pl
[14] Osowski S., Sieci neuronowe do przetwarzania informacji, Oficyna Wydawnicza Politechniki Warszawskiej, Warszawa, 2006.

[15] Śliwczyński, A. Koliński, P. Andrzejczyk, Organizacja i monitorowanie procesów produkcyjnych, Instytut Logistyki i Magazynowania, Poznań, 2013.

[16] Zuppo, C.M., Defining ICT in boundaryless world: the development of a working hierarchy, Marion Technical College (MTC), International Journal of Managing Information Technology (IJMIT) Vol. 4, No. 3, 2012.

[17] Żurada J., Barski M., Jędruch W., Sztuczne sieci neuronowe: podstawy teorii i zastosowania, Wydawnictwo Naukowe PWN, Warszawa. 1996. 